\title{
Using the intervention mapping protocol to reduce European preschoolers' sedentary behavior, an application to the ToyBox-Study
}

Ellen De Decker ${ }^{1 *}$, Marieke De Craemer ${ }^{1}$, Ilse De Bourdeaudhuij ${ }^{1}$, Vera Verbestel ${ }^{1}$, Kristin Duvinage², Violeta lotova ${ }^{3}$, Evangelia Grammatikaki ${ }^{4}$, Andreas Wildgruber ${ }^{5}$, Theodora Mouratidou ${ }^{6}$, Yannis Manios ${ }^{4}$ and Greet Cardon ${ }^{1}$

\begin{abstract}
Background: High levels of sedentary behavior are often measured in preschoolers, but only a few interventions have been developed to counteract this. Furthermore, detailed descriptions of interventions in preschoolers targeting different forms of sedentary behavior could not be located in the literature. The aim of the present paper was to describe the different steps of the Intervention Mapping Protocol used towards the development of an intervention component of the ToyBox-study focusing on decreasing preschoolers' sedentary behavior. The ToyBox-study focuses on the prevention of overweight in 4- to 6-year-old children by implementing a multi-component kindergarten-based intervention with family involvement in six different European countries.

Methods: Applying the Intervention Mapping Protocol, six different steps were systematically completed for the structured planning and development of the intervention. A literature search and results from focus groups with parents/caregivers and kindergarten teachers were used as a guide during the development of the intervention and the intervention materials.

Results: The application of the different steps in the Intervention Mapping Protocol resulted in the creation of matrices of change objectives, followed by the selection of practical applications for five different intervention tools that could be used at the individual level of the preschool child, at the interpersonal level (i.e., parents/caregivers) and at the organizational level (i.e., kindergarten teachers). No cultural differences regarding preschoolers' sedentary behavior were identified between the participating countries during the focus groups, so cultural and local adaptations of the intervention materials were not necessary to improve the adoption and implementation of the intervention.

Conclusions: A systematic and evidence-based approach was used for the development of this kindergarten-based family-involved intervention targeting preschoolers, with the inclusion of parental involvement. The application of the Intervention Mapping Protocol may lead to the development of more effective interventions. The detailed intervention matrices that were developed as part of the ToyBox-study can be used by other researchers as an aid in order to avoid repetitive work for the design of similar interventions.
\end{abstract}

Keywords: Kindergarten, Preschoolers, Sedentary behavior, Intervention Mapping Protocol

\footnotetext{
* Correspondence: ellen.dedecker@ugent.be

'Department of Movement and Sports Sciences, Ghent University,

Watersportlaan 2, 9000 Ghent, Belgium

Full list of author information is available at the end of the article
} 


\section{Background}

Sedentary behavior is often defined as activities involving sitting down [1]. Recently, the Sedentary Behavior Research Network suggested the use of a standardized definition of sedentary behavior. This definition describes that sedentary behavior includes activities that are characterized by an energy expenditure of $\leq 1.5$ Metabolic equivalent of Task (MET), mostly during sitting or in a reclining position (e.g., watching television (TV), using the computer) [2]. Recent studies found that higher levels of sedentary behavior were associated with negative health outcomes, like less desirable cognitive and behavioral outcomes $[3,4]$, and with a lower bone mineral content in children [5]. Furthermore, sedentary behavior (and in particular screen viewing behaviors) has been associated with overweight in children [6-8]. Consequently, different health-enhancing guidelines have been formulated that recommend limiting the length of time in sedentary behaviors in general [1,9-12], minimizing screen time including TV viewing and the use of other electronic media (e.g., DVD, computers, electronic games) to less than one to two hours per day in young children [13].

However, objective and subjective monitoring studies indicate that preschoolers (4 to 6 years) spend much of their time in sedentary activities [14-16]. Screen-based activities are generally included in preschoolers' daily routine [16], with reports that indicated that children below the age of six years watched almost two hours of TV per day [17]. Furthermore, parental reports in the study of Cardon and De Bourdeaudhuij indicated that preschoolers between 4- and 5-years-old viewed TV or played on the computer for an average of 74 minutes on weekdays and 140 minutes on weekends [18]. High levels of sedentary behavior are observed at home as well as at organized out-of-home care (e.g., in preschools or child-care centers), with great variability's of this behavior between centers $[19,20]$. Brown et al. for example reported that almost $89 \%$ of preschoolers' time at preschool was spent in a sedentary way [21], while Temple et al. reported that preschoolers spent 39.5 minutes per hour in sedentary behavior in family child care [22]. Preschoolers are not only sedentary during the time they spend inside the classroom; high sedentary behavior levels were also objectively measured during preschool recess $[23,24]$.

Although high levels of sedentary behavior are reported in different forms and settings, only a limited number of interventions focusing on decreasing this behavior has been conducted in preschoolers. Two review articles evaluated interventions focusing on decreasing screen time in children [25] and on limiting sedentary behavior [26]. The review of DeMattia et al. [26] included only one school-based intervention targeting preschoolers that executed a 7-session program with a weekly 20-minutes educational session in children between 2 and 5 years old [27]. Findings showed that such a classroom-based health promotion intervention in preschools resulted in a decrease in TV viewing by almost $25 \%$ in the intervention group, while the control group increased their TV viewing by almost $12 \%$. However, no differences were observed in terms of body mass index (BMI) between the two groups [27]. The second review by Wahi et al. [25] additionally reported the study by Epstein et al. [28]. This study aimed to reduce TV viewing and computer use in 4- to 7-year-old preschoolers with a BMI $\geq 75$ th $\mathrm{BMI}$ percentile by using the device 'the TV Allowance'. Children in the intervention group received a weekly time budget that could be spent on the TV Allowance to watch TV or play on the computer while the control group had free access to TV and computer. The results of this intervention showed that children in the intervention group reduced their TV viewing and computer use more compared to children in the control group [28]. Although a number of childhood overweight prevention interventions in different age groups (e.g., HELENA, IDEFICS, ENERGY) has been conducted targeting different energy-balanced related behaviors (e.g., physical activity, dietary intake), an intervention targeting different forms of sedentary behaviors (not only screen viewing behaviors but also the interruption of prolonged periods of sitting down) in preschoolers could not be identified. The ToyBox-study [29] aimed to develop and evaluate a 6-month intervention to prevent overweight in 4- to 6-year olds in six European countries (Belgium, Bulgaria, Germany, Greece, Spain and Poland). This study focused on increasing preschoolers' water consumption, increasing the consumption of healthy snacks, increasing daily physical activity levels and decreasing different forms of sedentary behavior. The development and the implementation of the ToyBox-intervention included four different intervention modules addressing the four different behaviors mentioned above. For the development of the ToyBox-study intervention, the Intervention Mapping Protocol (IMP) [30] was used to ensure that the development was done on a scientific and systematic basis. The current paper will only focus on the sedentary behavior intervention module and aims to provide information on how the different steps of the IMP were implemented, and to present the matrices developed. This will help planners of future interventions aiming to decrease sedentary behavior in preschoolers to develop their own modules and matrices.

\section{Methods}

The different steps included in the IMP are: 1) needs assessment, 2) preparing matrices of change objectives, 3 ) 
selecting theory-informed intervention methods and practical strategies, 4) producing intervention components and materials, 5) planning program adoption and implementation, and 6) evaluation planning (Figure 1) [30] (p.19). Two out of the six countries in this European study (Germany and Belgium) were responsible for the development of the different intervention modules, as described in the project's description of work. Other participating countries provided feedback on the developed intervention and approved the intervention components and materials.

\section{Step 1: needs assessment}

In the first step of the IMP, a needs assessment was executed to better understand the health problem of overweight in preschoolers and its association with sedentary behavior using the PRECEDE component [31] of the PRECEDE-PROCEDE model (Figure 2) [30] (p.36-37). This educational and ecological model in health program planning includes a sequence of steps and provides a detailed and well-structured approach for assessment procedures. During the first and the second phase of the PRECEDE component, quality of life indicators were investigated and a description of the health problem was formulated. Furthermore, because little is known about the link between sedentary behavior and overweight in preschoolers, the association between this behavior and overweight at the individual level was identified during the third phase of the PRECEDE model. Next to the behavioral analysis, an environmental analysis was performed, including the environmental factors at the interpersonal and organizational level that influence the health problem directly or through its behavioral causes. Because both parents/caregivers and preschool teachers have an important role in establishing behaviors, focus groups were executed at the interpersonal level to identify the influencing factors of preschoolers' sedentary behavior, to identify possible difficulties and barriers to decrease this behavior and to get a better insight into the personal determinants of both the parents/caregivers and the teachers. Furthermore, the most important predisposing (preferences and habits of preschoolers), reinforcing (behaviors, knowledge and attitudes of parents/caregivers and teachers) and enabling (rules, barriers) factors of preschoolers' sedentary behavior were collected during the last phase of the PRECEDE model [29]. The recruitment setting was country dependent, based on the country regulations and legislations. Specifically, in Germany, Bulgaria, Spain and Poland, recruitment was done in kindergartens, in Greece in kindergartens and in daycare centers and in Belgium in preschool settings. In order to ease reading, all these settings will be referred to as 'kindergartens' in this paper.

\section{Step 2: preparing matrices of change objectives}

In the second step, a program goal for the health outcome to be achieved by the intervention was formulated. During this step of the IMP, the logic model of change

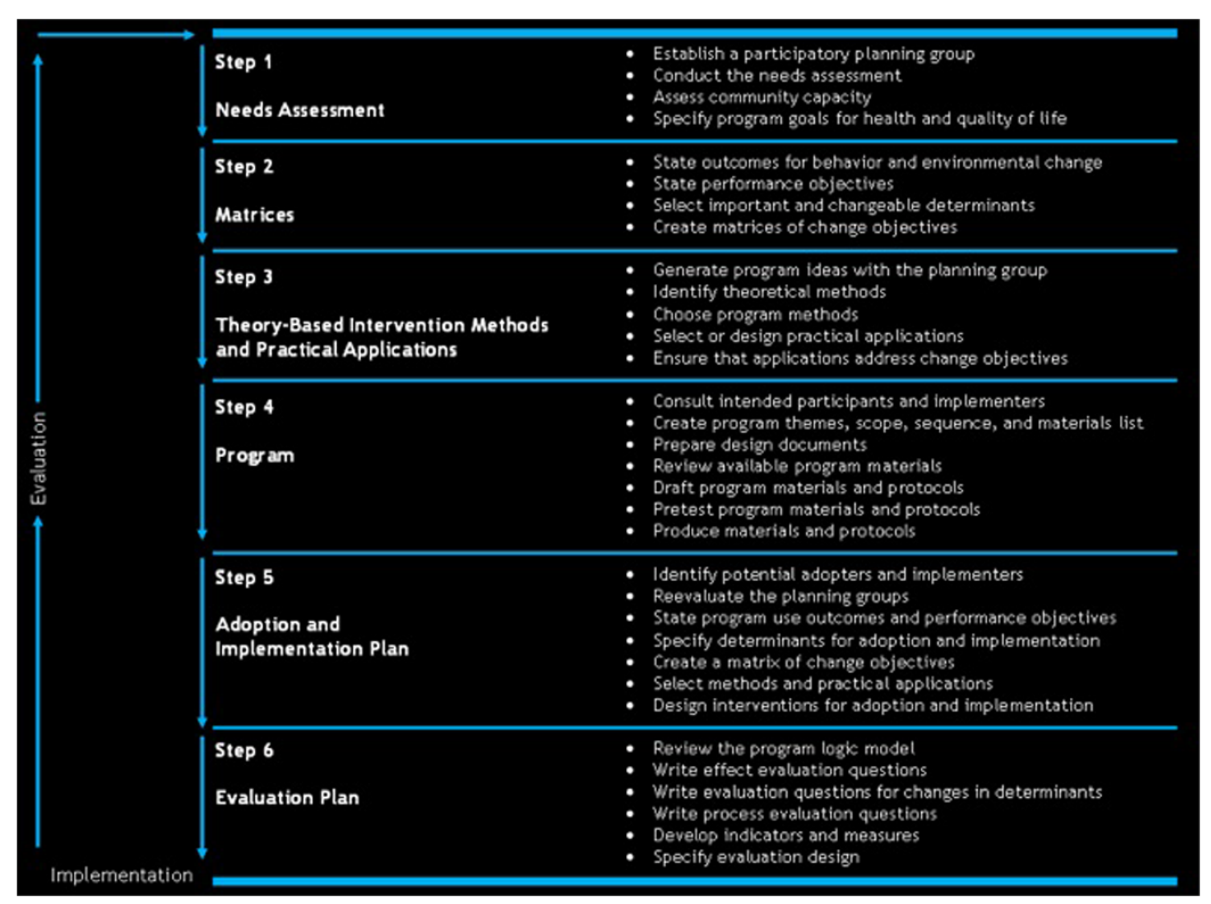

Figure 1 Overview of the Intervention Mapping steps and corresponding tasks. 


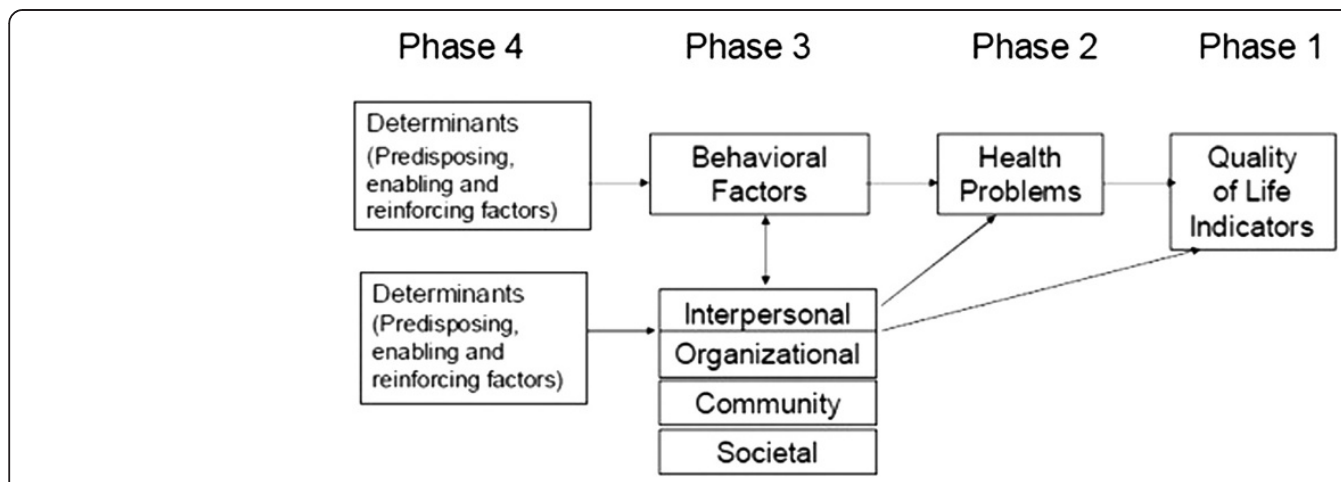

Figure 2 Overview of the PRECEDE model.

was used to state the behavioral and environmental changes in terms of what is necessary to achieve the health outcome [30] (p.37). First, performance objectives were formulated to obtain behavioral and environmental outcomes that the intervention seeks to accomplish. These performance objectives state what the intervention participants have to do or how the environment has to be modified in order to achieve the health outcome. Based on the information derived from the focus groups and based on a literature search, determinants of behavioral and environmental outcomes were examined and listed. The list of potential determinants was then refined into a final determinant list by making a selection of each determinant in terms of relevance (strength of the association with sedentary behavior) and changeability (likelihood that the intervention could influence a change in the determinant). Finally, the selected determinants were crossed with the formulated performance objectives to generate matrices with change objectives. The change objectives were entered into cells formed at the intersection of each performance objective and determinant. These change objectives specify what needs to change in the determinants of behavioral or environmental outcomes in order to accomplish the performance objectives.

\section{Step 3: selecting theory-informed intervention methods and practical strategies}

In the third step of the IMP, theoretical methods that can influence changes in the selected determinants were identified, based on a list including all change objectives by determinant. All change objectives that had to do with a specific determinant (e.g., knowledge) were listed and theoretical methods (e.g., active learning) were then matched with the corresponding determinant, resulting in a list including all change objectives by determinant with respective methods. Once the theoretical methods were selected, they were then translated into creative applications. The development of creative applications was guided by the formulated change objectives in the previous step of the IMP, and was also based on suggestions made by the teachers and the parents/caregivers during the focus groups.

Step 4: producing intervention components and materials In the fourth step of the intervention, the scope, the sequence, the themes and a list of necessary intervention materials were made. Suggestions made by the parents/ caregivers and the teachers were used to prepare design documents for the production of the intervention materials that met the program objective. These design documents included a detailed description of the audience (i.e., preschoolers) and the contexts in which the material will be used. Once the design documents were developed, a review of available materials was done against the matrices and a list of methods and applications. Once initial design documents were created, culturally relevant program materials were developed.

\section{Step 5: planning program adoption and implementation} During the fifth step of the IMP, the intervention adoption and implementation was planned. Based on the first step of the IMP, teachers and parents/caregivers were chosen as intervention adopters and implementers, and local differences between and within the participating European countries were considered. Next, a clear implementation plan was developed to inform the researchers in the participating countries about the different core components of the intervention and about details of the steps in delivering the intervention. The emphasis of the implementation plan was placed on achieving a high level of fidelity and completeness, with the inclusion of implementation options to make the intervention more flexible for easy adoption.

\section{Step 6: evaluation planning}

The last step of the IMP included the development of a plan for the evaluation of the outcomes and the process 
of the intervention. Next to the outcome evaluation, a process evaluation was performed and indicated the fidelity of the intervention delivery across the different countries. The last part of the sixth step in the IMP included the evaluation of the efficacy of the program in terms of costs and effects.

\section{Results}

All the different steps of the IMP will be described briefly below, but a more detailed description will be provided for step 2 to step 4 .

\section{Step 1: needs assessment}

As part of the needs assessment, secondary data analyses were first executed between June 2010 and August 2010, indicating that the prevalence of overweight and obesity ranged from $8 \%$ to $30 \%$ and from $1 \%$ to $13 \%$ respectively in preschoolers between 4- and 7-years-old across the participating European countries [32]. A literature search was started in July 2010 and found moderate evidence for a positive association between TV viewing and overweight in preschool-aged children [33]. Results of the focus groups with European parents/caregivers executed between October 2010 and January 2011 indicated that preschoolers tend to like watching TV, with most parents/caregivers not expressing worries about this behavior. The most important influencing factors of preschoolers' screen time were the weather conditions and parental habits at home [34]. According to the teachers, preschoolers do not sit very much at kindergarten. The lack of play space and play equipment were perceived as potentially influencing factors of preschoolers' sedentary behavior during kindergarten hours [35].

\section{Step 2: preparing matrices of change objectives}

Based on the information out of the first step of the IMP, three program objectives for the sedentary behavior intervention were formulated. The program objective for the individual level of the intervention was: 'Children between 4- and 6-years-old decrease their sitting time (screen viewing activities and other sedentary activities) by 10\% at home and during their time at kindergarten at the end of the intervention'. Based on the program objectives, different performance objectives were formulated at the individual level of the child and for the parents/ caregivers and teachers at the interpersonal and organizational level. An overview of the program objectives and performance objectives for each level of the intervention can be found in Table 1 .

After all performance objectives were formulated for the individual, the interpersonal and the organizational level separately, personal determinants of sedentary behavior were listed for each level based on the results of the focus groups and a literature search. The selection of the determinants was based on their changeability, importance and strength of relationship with preschoolers' behavior. The personal determinants selected for preschoolers were (i) attitude, (ii) preference, (iii) selfefficacy and (iv) capability. For parents/caregivers at the interpersonal level, the personal determinants included (i) self-efficacy, (ii) knowledge, (iii) attitude, (iv) habit and (v) social influence. Finally, for kindergarten teachers at the organizational level, (i) self-efficacy, (ii) habit, (iii) knowledge, (iv) attitude, and (v) social influence were selected as personal determinants. Once the personal determinants were listed, matrices of change objectives were created by crossing performance objectives with the selected determinants between January 2011 and the end of April 2011. Because performance objectives were formulated for each level of the intervention separately, a separate matrix was constructed for each level of the intervention (Table 2, 3 and 4). For example, the performance objective at the individual level for preschoolers to decrease their total sitting time per day at kindergarten was crossed with the determinant 'preference' and resulted in the change objective 'Children prefer to stand up instead of sitting down in the classroom or at kindergarten'. The formulated change objectives were stated with an action word [30] (p.293), followed by a statement of what is expected to result from the intervention.

\section{Step 3: selecting theory-informed intervention methods and practical strategies}

Methods from theory and from the literature that are capable of influencing changes in the determinants were chosen during the third step of the IMP. A systematic review that was conducted as part of the ToyBox-study identified effective behavioral models, methods and behavior change strategies that could be used in preschool children [36]. First, all determinants included in the matrices at different intervention levels were listed and were matched with methods derived from a theory. These methods were carefully considered for use in our intervention. For example, the formulated change objective 'Children express positive feelings towards switching from sitting down to standing up for some activities' was the result of crossing the performance objective 'Switching from sitting down to standing up for some activities' with the determinant 'attitude'. The selected theoretical method that corresponded with the determinant 'attitude' in order to reach the change objective was 'direct experience' [30] (p.338). After the theoretical method was chosen, theoretical parameters and characteristics of the context were checked and the selected method was translated into a creative application. For example, a creative application that was formulated by the method of 'direct experience' was to decrease preschoolers' 
Table 1 Overview of the formulated program and performance objectives for each level of the intervention

\begin{tabular}{lll}
\hline Level of the intervention & Target group & Program objective \\
\hline Individual level & Preschool child & $\begin{array}{l}\text { Children between 4- and 6-years-old } \\
\text { decrease their sitting time (screen } \\
\text { viewing activities and other sedentary } \\
\text { activities) by } 10 \% \text { at home and during } \\
\text { their time at kindergarten at the end } \\
\text { of the intervention }\end{array}$
\end{tabular}

\author{
Performance objective \\ PO.1. Children decrease their total \\ sitting time per day at kindergarten. \\ PO.2. Children decrease their total \\ sitting time per day at home or \\ during leisure time. \\ PO.3. Children limit screen viewing \\ to one hour per day at kindergarten. \\ PO.4. Children limit screen viewing \\ to one hour per day or less at \\ home (with help from their \\ parents/caregivers). \\ PO.5. Children switch from sitting \\ down to standing up for some activities. \\ PO.1. Parents/caregivers limit \\ preschoolers' screen viewing activities \\ to one hour per day.
}

Interpersonal level

Parents/caregivers of preschoolers in the home environment
Parents/caregivers decrease their child's sedentary time by $10 \%$ and limit screen viewing activities at home to less than one hour per day after the intervention.
PO.2. Parents/caregivers motivate (verbally) their children to do other activities instead of screen viewing activities.

PO.3. Parents/caregivers do other activities together with their child instead of screen viewing activities.

PO.4. Parents/caregivers are a role model for their children and limit their own time sitting down.

PO.1. Teachers use different strategies (e.g., classroom environmental changes, performing standing classroom activities, etc.) to decrease preschoolers' total sitting time per day at kindergarten.

PO.2. Teachers give assignments that the preschoolers need to fulfill standing up.

PO.3. Teachers encourage the preschoolers to stand up when they are sitting down at the playground.

PO.4. Teachers are a role model for the preschoolers and limit sitting down themselves.

P0.5. Teachers encourage the preschoolers to switch from sitting down to standing up. sedentary behavior by completing activities (e.g., coloring, painting) standing up, with preschoolers directly experiencing what it is to complete these activities while standing up. Furthermore, for the translation of the methods into applications, the suggestions that parents/caregivers and teachers formulated during the focus groups were used. For example, kindergarten teachers indicated that providing information about sedentary behavior to preschoolers can be done by telling the preschoolers a story about a character whose levels of daily sedentary behavior they would like to decrease. Table 5 provides an overview of all the methods and applications that were selected and used to achieve the change objectives for each level of the intervention.

Step 4: producing intervention components and materials Based on the selected methods and applications, a comprehensive intervention program and a list of intervention materials were compiled. The program materials for the individual level and the organizational level included a general teachers' guide and a hand book with classroom activities. In the teachers' guide, some general information was provided (e.g., a definition of sedentary behavior, prevalence of preschoolers' sedentary 
Table 2 Matrix for preschoolers at the individual level of the ToyBox-study intervention

\begin{tabular}{|c|c|c|c|c|}
\hline \multirow{2}{*}{$\begin{array}{l}\text { Performance } \\
\text { objectives } \\
\text { (Preschoolers) } \\
\end{array}$} & \multicolumn{4}{|l|}{ Personal determinants } \\
\hline & Attitude & Preference & Self-efficacy & Capability \\
\hline $\begin{array}{l}\text { PO.1. Children } \\
\text { decrease their total } \\
\text { sitting time per day at } \\
\text { kindergarten. }\end{array}$ & $\begin{array}{l}\text { A.1. Children express positive } \\
\text { feelings towards devoting less } \\
\text { time sitting down at } \\
\text { kindergarten. }\end{array}$ & $\begin{array}{l}\text { P.1. Children prefer to stand } \\
\text { up instead of sitting down in } \\
\text { the classroom or at } \\
\text { kindergarten. }\end{array}$ & $\begin{array}{l}\text { SE.1. Children express } \\
\text { confidence about decreasing } \\
\text { their total sitting time per day } \\
\text { at kindergarten, even when } \\
\text { the other children want to sit } \\
\text { down/are sitting down. }\end{array}$ & $\begin{array}{l}\text { C.1. Children are capable of } \\
\text { decreasing their total sitting } \\
\text { time per day at } \\
\text { kindergarten. }\end{array}$ \\
\hline
\end{tabular}

\section{PO.2. Children}

decrease their total

sitting time per day at

home or during leisure

time.

A.2. Children express positive feelings towards being less sedentary, at home or during leisure time.

A.3. Children express positive feelings towards limiting their screen viewing time by doing other non-sedentary activities at kindergarten.
P.2. Children prefer to stand up instead of sitting down at home or during leisure time.

\section{SE.2. Children express}

confidence about decreasing their total sitting time per day at home or during leisure time, even when their siblings are sitting down.

P.3. Children indicate that they prefer to limit their screen viewing (e.g., TV viewing time, computer time, etc.) to less than one hour per day at kindergarten.

\begin{abstract}
A.4. Children express positive feelings towards limiting their screen viewing time (with help from their parents/ caregivers) by doing other activities at home.
\end{abstract}

SE.3. Children express confidence about limiting their screen viewing to less than one hour per day at kindergarten, even when the other children are watching TV, playing on the computer or doing other screen viewing activities.

SE.4. Children express confidence about limiting their screen viewing time to one hour per day (with help from their parents/caregivers) or less at home, even when
PO.3. Children limit screen viewing to one hour per day at kindergarten.
P.4. Children prefer to limit their screen viewing (e.g., TV viewing time, computer time, etc.) to one hour per day or less at home (with help from their parents/caregivers). their siblings are watching TV, playing on the computer or doing other screen viewing activities.

PO.5. Children switch from sitting down to standing up for some activities.
A.5. Children express positive feeling towards switching from sitting down to standing up for some activities.
P.5. Children prefer to switch from sitting down to standing up for some activities.
SE.5.a. Children express confidence about switching from sitting down to standing up, even when the other children do these activities sitting down.

SE.5.b. Children express confidence about switching from sitting down to standing up, even when the teacher does not give prompts to do this.
C.2. Children are capable of decreasing their total sitting time per day at home or during leisure time.

C.3. Children are capable of limiting their screen viewing time to less than one hour per day at preschool.

C.4. Children are capable of limiting their screen viewing time to one hour per day or less at home (with help from their parents/ caregivers).
C.5. Children are capable of switching from sitting down to standing up for some activities.

\footnotetext{
PO.: performance objective.
}

Behavior: Decrease preschoolers' sedentary behavior; Program objective: Children between 4- and 6-years old decrease their sitting time (screen viewing activities and other sedentary activities) by $10 \%$ at home and during their time at kindergarten at the end of the intervention.

behavior). The handbook consisted of three different parts. First, environmental changes that teachers could perform in their classroom were suggested. For example, teachers could put the sandbox on top of a table so that the preschoolers have to stand up to play with the sand in the sandbox instead of sitting down. Secondly, fun movement breaks were provided for the teachers to implement during the day or on days when no physical education classes were carried out at kindergarten (e.g., asking the preschoolers to walk around in the classroom and stand still when a certain word is said). Kindergarten teachers were encouraged to set time rules for interrupting preschoolers' sedentary behavior during the school hours (e.g., every 30-40 minutes per day) and to execute two movement breaks in the morning and two in the afternoon. Finally, the third part of the handbook included three stories about a kangaroo and his friends. Teachers could read these stories to increase preschoolers' knowledge, enhance preschoolers' skills and their self-efficacy. Implementing activities of the sedentary behavior intervention for a minimum of one hour per week was recommended. 
Table 3 Matrix for parents/caregivers at the interpersonal level of the ToyBox-study intervention

Performance objectives Personal determinants

\begin{tabular}{lll} 
(Parents/caregivers) & Self-efficacy & Knowledge \\
\hline PO.1. Parents/caregivers & SE.1.a. Parents/caregivers express & K.1.a. Parents/caregivers know that it is \\
limit preschoolers' screen & confidence that they can use & recommended to limit screen \\
viewing activities to one & $\begin{array}{l}\text { different strategies to limit screen } \\
\text { viewing activities even when their }\end{array}$ & $\begin{array}{l}\text { activities of their child to one hour per } \\
\text { hour per day. }\end{array}$ \\
& $\begin{array}{l}\text { child wants to continue doing } \\
\text { screen viewing activities. }\end{array}$ & \\
& SE.1.b. Parents/caregivers express & K.1.b. Parents/caregivers list different \\
& confidence that they can use & strategies to limit screen viewing \\
& different strategies to limit screen & activities.
\end{tabular}

viewing activities even when their

child is nagging.

PO.2. Parents/caregivers motivate (verbally) the children to do other activities instead of screen viewing activities.

PO.3. Parents/caregivers $\begin{array}{ll}\text { do other activities } & \text { confidence that they can do } \\ \text { together with their child activities with their child which }\end{array}$ instead of screen viewing activities.

SE.2. Parents/caregivers express confidence that they can motiva heir child to do other activities instead of screen viewing activities even when their child is nagging.

SE.3. Parents/caregivers express activities with their child which are not screen viewing activities even
when their child only wants to do screen viewing activities.

PO.4. Parents/caregivers SE.4.a. Parents/caregivers express are a role model for their confidence that they can be a role children and limit their model for their child, even when own time sitting down. they had a rough day.

SE.4.b. Parents/caregivers express confidence that they can be a role confidence that they can be a role
model for their child, even when they are tired or they are not in the mood.

SE.4.c. Parents/caregivers express confidence that they can be a role model for their child.
Attitude

A.1. Parents/caregivers express positive

feelings about the benefits that

limiting the screen viewing activities one hour per day by using different strategies has for their child.

strategies to limit screen viewing
Habit H1.a. Parents/

caregivers plan no or only a limited amount of screen viewing activities of their child

H.1.b. Parents/ caregivers only turn on the TV after a certain time or at a certain moment (e.g. at $7 \mathrm{pm}$ ).

H.1.c. Parents/

caregivers turn off the TV after a certain program or show or after a certain time.

K.2. Parents/caregivers know how to motivate their child to do other activities instead of screen viewing activities (e.g., tips, tricks).

A.2. Parents/caregivers express positive feelings about the benefits that doing other activities instead of screen viewing activities has for their child.

K.3. Parents/caregivers list activities that can be done instead of screen viewing activities (e.g., tips, tricks, ...

A.3. Parents/caregivers express positive A.3. Parents/caregivers express positive
feelings about the benefits that doing other activities together with their child instead of screen viewing activities has for their child.

\section{H.3. Parents/caregivers} plan to do other with their child before they turn on the TV at a certain time.

SI.2. Parents/caregivers indicate that they are able to motivate their child to do other activities instead of screen viewing activities even when their colleagues/ friends/ neighbours don't motivate their own child.

K.4. Parents/caregivers know that being a role model for their child and limit their own time sitting down, encourages their child to also limit his/her time sitting down because they will copy this behavior.

A.4. Parents/caregivers express positive H.4. Parents/caregivers change their own feelings about the benefits of being a change their own $\begin{array}{ll}\text { role model for their children has for } & \text { habit and turn of the } \\ \text { their child because the child will copy } & \text { TV if they are together }\end{array}$

with their child. in their daily routine.

\section{Social influence}

PO.: performance objective.

Behavior: Decrease preschoolers' sedentary behavior; Program objective: Parents/caregivers decrease their child's sedentary time by $10 \%$ and limit screen viewing activities at home to less than one hour per day after the intervention. 


\begin{tabular}{|c|c|c|c|c|c|}
\hline \multirow[t]{2}{*}{ Performance objectives (teachers) } & \multicolumn{5}{|l|}{ Personal determinants } \\
\hline & Self-efficacy & Habit & Knowledge & Attitude & Social influence \\
\hline \multirow[t]{2}{*}{$\begin{array}{l}\text { PO.1. Teachers use different strategies } \\
\text { (e.g., classroom environmental } \\
\text { changes, performing standing } \\
\text { classroom activities, etc.) to decrease } \\
\text { preschoolers' total sitting time per day } \\
\text { in kindergarten. }\end{array}$} & $\begin{array}{l}\text { SE.1.a. Teachers express confidence } \\
\text { that they can use different strategies } \\
\text { to decrease preschoolers' total } \\
\text { sitting time in kindergarten even } \\
\text { when they have a tight schedule to } \\
\text { follow. }\end{array}$ & $\begin{array}{l}\text { H.1. Teachers plan to use } \\
\text { different strategies to } \\
\text { decrease preschoolers' } \\
\text { total sitting time into their } \\
\text { daily routine. }\end{array}$ & $\begin{array}{l}\text { K.1.a. Teachers list } \\
\text { different strategies to } \\
\text { decrease } \\
\text { preschoolers' total } \\
\text { sitting time a day. }\end{array}$ & $\begin{array}{l}\text { A.1. Teachers express positive } \\
\text { feelings about the benefits of } \\
\text { using different strategies to } \\
\text { decrease preschoolers' total } \\
\text { sitting time. }\end{array}$ & $\begin{array}{l}\text { SI.1. Teachers indicate that they use } \\
\text { different strategies to decrease } \\
\text { preschoolers' total sitting time per } \\
\text { day in kindergarten even when } \\
\text { other teachers stick to sedentary } \\
\text { activities. }\end{array}$ \\
\hline & $\begin{array}{l}\text { SE.1.b. Teachers express confidence } \\
\text { that they can use different strategies } \\
\text { to decrease preschoolers' total } \\
\text { sitting time in kindergarten even } \\
\text { when the preschoolers are lively. }\end{array}$ & & $\begin{array}{l}\text { K.1.b. Teachers know } \\
\text { different strategies to } \\
\text { decrease } \\
\text { preschoolers' total } \\
\text { sitting time per day in } \\
\text { kindergarten. }\end{array}$ & & \\
\hline $\begin{array}{l}\text { PO.2. Teachers give assignments that } \\
\text { the preschoolers need to fulfil } \\
\text { standing up. }\end{array}$ & $\begin{array}{l}\text { SE.2. Teachers express confidence } \\
\text { that they can give assignments that } \\
\text { the preschoolers need to fulfil } \\
\text { standing up even when they need } \\
\text { to rearrange their classroom. }\end{array}$ & $\begin{array}{l}\text { H.2. Teachers plan to give } \\
\text { assignments that the } \\
\text { preschoolers need to fulfill } \\
\text { standing up. }\end{array}$ & $\begin{array}{l}\text { K.2. Teachers know } \\
\text { assignments that the } \\
\text { preschoolers need to } \\
\text { fulfill standing up. }\end{array}$ & $\begin{array}{l}\text { A.2. Teachers express positive } \\
\text { feelings about the benefits of } \\
\text { giving assignments that } \\
\text { preschoolers need to fulfill } \\
\text { standing up. }\end{array}$ & $\begin{array}{l}\text { SI.2. Teachers indicate that they } \\
\text { plan to give assignments that the } \\
\text { preschoolers need to fulfill } \\
\text { standing up even when other } \\
\text { teachers stick to fulfilling } \\
\text { assignments sitting down. }\end{array}$ \\
\hline $\begin{array}{l}\text { PO.3. Teachers encourage the } \\
\text { preschoolers to stand up when they } \\
\text { are sitting down at the playground. }\end{array}$ & $\begin{array}{l}\text { SE.3. Teachers express confidence } \\
\text { that they can encourage the } \\
\text { preschoolers to stand up at the } \\
\text { playground even when there is } \\
\text { already a lot of noise and } \\
\text { commotion. }\end{array}$ & $\begin{array}{l}\text { H.3. Teachers plan to } \\
\text { encourage the } \\
\text { preschoolers to stand up } \\
\text { at the playground every } \\
\text { time they see the } \\
\text { preschoolers sitting down. }\end{array}$ & & $\begin{array}{l}\text { A.3. Teachers express positive } \\
\text { feelings about the benefits } \\
\text { that encouraging the } \\
\text { preschoolers to stand up at } \\
\text { the playground has for the } \\
\text { preschoolers. }\end{array}$ & $\begin{array}{l}\text { SI.3. Teachers encourage the } \\
\text { preschoolers to stand up when } \\
\text { they are sitting down at the } \\
\text { playground even when other } \\
\text { teachers don't do this. }\end{array}$ \\
\hline $\begin{array}{l}\text { PO.4. Teachers are a role model for } \\
\text { the preschoolers and limit sitting } \\
\text { down themselves. }\end{array}$ & $\begin{array}{l}\text { SE.4. Teachers express confidence } \\
\text { that they are a role model for the } \\
\text { preschoolers in limiting sitting } \\
\text { down even when they are tired. }\end{array}$ & & $\begin{array}{l}\text { K.4. Teachers know } \\
\text { that being a role } \\
\text { model for the } \\
\text { preschoolers } \\
\text { encourages the } \\
\text { preschoolers to sit } \\
\text { down less. }\end{array}$ & $\begin{array}{l}\text { A.4. Teachers express positive } \\
\text { feelings about being a role } \\
\text { model for the preschoolers } \\
\text { by limiting their own time } \\
\text { sitting down. }\end{array}$ & \\
\hline $\begin{array}{l}\text { PO.5. Teachers encourage the } \\
\text { preschoolers to switch from sitting } \\
\text { down to standing up. }\end{array}$ & $\begin{array}{l}\text { SE.5. Teachers express confidence } \\
\text { that they can encourage the } \\
\text { preschoolers to switch from sitting } \\
\text { down to standing up, even when } \\
\text { they don't have the appropriate } \\
\text { tools. }\end{array}$ & $\begin{array}{l}\text { H.5. Teachers plan to } \\
\text { encourage the } \\
\text { preschoolers to switch } \\
\text { from sitting down to } \\
\text { standing up into their } \\
\text { daily routine. }\end{array}$ & $\begin{array}{l}\text { K.5. Teachers know } \\
\text { that switching from } \\
\text { sitting down to } \\
\text { standing up is } \\
\text { beneficiary for the } \\
\text { preschoolers. }\end{array}$ & $\begin{array}{l}\text { A.5. Teachers express positive } \\
\text { feeling about the benefits of } \\
\text { encouraging the preschoolers } \\
\text { to switch from sitting down } \\
\text { to standing up. }\end{array}$ & \\
\hline
\end{tabular}

PO.: performance objective.

Behavior: Decrease preschoolers' sedentary behavior; Program objective: Teachers decrease preschoolers' sedentary time by $10 \%$ at preschool and limit screen viewing activities to less than one hour daily after the intervention. 
Table 5 Theoretical methods and applications for achieving the change objectives at each level of the ToyBox-study intervention

\begin{tabular}{|c|c|c|c|c|c|c|}
\hline $\begin{array}{l}\text { Level of the } \\
\text { intervention }\end{array}$ & Determinant & Change objective * & Method † & Related theory $¥$ & Application & $\begin{array}{l}\text { Evaluation methods or } \\
\text { measures }\end{array}$ \\
\hline \multirow[t]{19}{*}{ PRESCHOOLERS } & \multirow[t]{7}{*}{ Attitude } & $\begin{array}{l}\text { A.1., A.2., A.3., } \\
\text { A.4., A.5. }\end{array}$ & Modeling & $\mathrm{SCT}$ & Stories of the kangaroo & Core questionnaire \\
\hline & & A.1., A.3., A.4., A.5. & Active learning & $\mathrm{SCT}$ & $\begin{array}{l}\text { Classroom activities done at } \\
\text { kindergarten listed in the } \\
\text { handbook }\end{array}$ & Process evaluation \\
\hline & & \multirow[t]{2}{*}{$\begin{array}{l}\text { A.1., A.2., A.3., } \\
\text { A.4., A.5. }\end{array}$} & \multirow[t]{2}{*}{ Direct experience } & \multirow[t]{2}{*}{$\mathrm{TL}$} & $\begin{array}{l}\text { Activities done while standing } \\
\text { up (provided in the handbook } \\
\text { and in the movement breaks) }\end{array}$ & $\begin{array}{l}\text { Core questionnaire } \\
\text { Process evaluation }\end{array}$ \\
\hline & & & & & $\begin{array}{l}\text { Classroom activities done at } \\
\text { kindergarten listed in the } \\
\text { handbook }\end{array}$ & Process evaluation \\
\hline & & \multirow[t]{2}{*}{ A.1. } & \multirow[t]{2}{*}{ Repeated exposure } & \multirow[t]{2}{*}{$\mathrm{TL}$} & $\begin{array}{l}\text { Repeated interruption } \\
\text { moments at kindergarten }\end{array}$ & $\begin{array}{l}\text { Objectively measured } \\
\text { sedentary time with the } \\
\text { accelerometer }\end{array}$ \\
\hline & & & & & $\begin{array}{l}\text { Classroom activities done at } \\
\text { kindergarten listed in the } \\
\text { handbook }\end{array}$ & Process evaluation \\
\hline & & A.4. & $\begin{array}{l}\text { Consciousness raising } \\
\text { (providing information) }\end{array}$ & $\mathrm{HBM}$ & Stories of the kangaroo & Core questionnaire \\
\hline & \multirow[t]{4}{*}{ Preference } & $\begin{array}{l}\text { P.1., P.2., P.3.a., } \\
\text { P.3.b., P.4., P.5. }\end{array}$ & Modeling & $\mathrm{SCT}$ & Stories of the kangaroo & Core questionnaire \\
\hline & & P.1., P.2., P.5. & Active learning & $\mathrm{SCT}$ & $\begin{array}{l}\text { Classroom activities done at } \\
\text { kindergarten listed in the } \\
\text { handbook }\end{array}$ & Process evaluation \\
\hline & & \multirow[t]{2}{*}{ P.1., P.2., } & \multirow[t]{2}{*}{ Direct experience } & \multirow[t]{2}{*}{$\mathrm{TL}$} & $\begin{array}{l}\text { Activities done while standing } \\
\text { up (provided in the handbook } \\
\text { and in the movement breaks) }\end{array}$ & $\begin{array}{l}\text { Core questionnaire } \\
\text { Process evaluation }\end{array}$ \\
\hline & & & & & $\begin{array}{l}\text { Classroom activities done at } \\
\text { kindergarten listed in the } \\
\text { handbook }\end{array}$ & Process evaluation \\
\hline & \multirow[t]{4}{*}{ Self-efficacy } & $\begin{array}{l}\text { SE.1., SE.2., SE.3., } \\
\text { SE.4., SE.5.a., SE.5.b. }\end{array}$ & Active learning & $\mathrm{SCT}$ & $\begin{array}{l}\text { Classroom activities done at } \\
\text { kindergarten listed in the } \\
\text { handbook }\end{array}$ & Process evaluation \\
\hline & & \multirow[t]{2}{*}{$\begin{array}{l}\text { SE.1., SE.2., SE.3., } \\
\text { SE.4., SE.5.a., SE.5.b. }\end{array}$} & \multirow[t]{2}{*}{ Direct experience } & \multirow[t]{2}{*}{$\mathrm{TL}$} & $\begin{array}{l}\text { Activities done while standing } \\
\text { up (provided in the handbook } \\
\text { and in the movement breaks) }\end{array}$ & $\begin{array}{l}\text { Core questionnaire } \\
\text { Process evaluation }\end{array}$ \\
\hline & & & & & $\begin{array}{l}\text { Classroom activities done at } \\
\text { kindergarten listed in the } \\
\text { handbook }\end{array}$ & Process evaluation \\
\hline & & $\begin{array}{l}\text { SE.1., SE.2., SE.3., } \\
\text { SE.4., SE.5.a., SE.5.b. }\end{array}$ & Modeling & $\mathrm{SCT}$ & Stories of the kangaroo & Core questionnaire \\
\hline & \multirow[t]{4}{*}{ Capability } & C.1., C.2., C.5. & Active learning & $\mathrm{SCT}$ & $\begin{array}{l}\text { Classroom activities done at } \\
\text { kindergarten listed in the } \\
\text { handbook }\end{array}$ & Process evaluation \\
\hline & & $\begin{array}{l}\text { C.1., C.2., C.3., } \\
\text { C.4., C.5. }\end{array}$ & Modeling & $\mathrm{SCT}$ & Stories of the kangaroo & Core questionnaire \\
\hline & & \multirow[t]{2}{*}{ C.1., C.2. } & \multirow[t]{2}{*}{ Verbal persuasion } & \multirow[t]{2}{*}{$\mathrm{SCT}$} & Stories of the kangaroo & Core questionnaire \\
\hline & & & & & $\begin{array}{l}\text { Classroom activities done at } \\
\text { kindergarten listed in the } \\
\text { handbook }\end{array}$ & Process evaluation \\
\hline \multirow[t]{3}{*}{$\begin{array}{l}\text { PARENTS/ } \\
\text { CAREGIVERS }\end{array}$} & \multirow[t]{3}{*}{ Self-efficacy } & $\begin{array}{l}\text { SE.1.a, SE.1.b., SE.2., } \\
\text { SE.3., SE.4.a., SE.4.b., } \\
\text { SE.4.c. }\end{array}$ & Guided practice & $\mathrm{SCT}$ & Newsletters & $\begin{array}{l}\text { Core questionnaire } \\
\text { Process evaluation } \\
\text { parents/caregivers }\end{array}$ \\
\hline & & \multirow[t]{2}{*}{$\begin{array}{l}\text { SE.1.a., SE.1.b., SE.3., } \\
\text { SE.4.a., SE.4.b., SE.4.c. }\end{array}$} & \multirow[t]{2}{*}{ Modeling } & \multirow[t]{2}{*}{$\mathrm{SCT}$} & Tip cards & $\begin{array}{l}\text { Core questionnaire } \\
\text { Process evaluation } \\
\text { parents/caregivers }\end{array}$ \\
\hline & & & & & Newsletters & $\begin{array}{l}\text { Core questionnaire } \\
\text { Process evaluation } \\
\text { parents/caregivers }\end{array}$ \\
\hline
\end{tabular}


Table 5 Theoretical methods and applications for achieving the change objectives at each level of the ToyBox-study intervention (Continued)

\begin{tabular}{|c|c|c|c|c|c|c|}
\hline & & \multirow[t]{3}{*}{ SE.1.b, SE.2., SE.3. } & \multirow[t]{3}{*}{ Verbal persuasion } & \multirow[t]{3}{*}{$\mathrm{SCT}$} & Tip cards & $\begin{array}{l}\text { Core questionnaire } \\
\text { Process evaluation } \\
\text { parents/caregivers }\end{array}$ \\
\hline & & & & & Newsletters & $\begin{array}{l}\text { Core questionnaire } \\
\text { Process evaluation } \\
\text { parents/caregivers }\end{array}$ \\
\hline & & & & & Poster & $\begin{array}{l}\text { Core questionnaire } \\
\text { Process evaluation } \\
\text { parents/caregivers }\end{array}$ \\
\hline & & \multirow[t]{2}{*}{ SE.1.b., SE.2. } & \multirow[t]{2}{*}{ Goal setting } & \multirow[t]{2}{*}{ GST } & Newsletters & $\begin{array}{l}\text { Core questionnaire } \\
\text { Process evaluation } \\
\text { parents/caregivers }\end{array}$ \\
\hline & & & & & Tip cards & $\begin{array}{l}\text { Core questionnaire } \\
\text { Process evaluation } \\
\text { parents/caregivers }\end{array}$ \\
\hline & & \multirow[t]{3}{*}{ SE.2. } & \multirow[t]{3}{*}{$\begin{array}{l}\text { Consciousness } \\
\text { raising (providing } \\
\text { information) }\end{array}$} & \multirow[t]{3}{*}{$\mathrm{HBM}$} & Tip cards & $\begin{array}{l}\text { Core questionnaire } \\
\text { Process evaluation } \\
\text { parents/caregivers }\end{array}$ \\
\hline & & & & & Newsletters & $\begin{array}{l}\text { Core questionnaire } \\
\text { Process evaluation } \\
\text { parents/caregivers }\end{array}$ \\
\hline & & & & & $\begin{array}{l}\text { Parent-child activities at } \\
\text { kindergarten }\end{array}$ & $\begin{array}{l}\text { Core questionnaire } \\
\text { Process evaluation } \\
\text { parents/caregivers }\end{array}$ \\
\hline & & \multirow[t]{2}{*}{ SE.4.b., SE.4.c. } & \multirow[t]{2}{*}{ Discussion } & \multirow[t]{2}{*}{ TIP } & $\begin{array}{l}\text { Parent-child activities at } \\
\text { kindergarten }\end{array}$ & $\begin{array}{l}\text { Core questionnaire } \\
\text { Process evaluation } \\
\text { parents/caregivers }\end{array}$ \\
\hline & & & & & Newsletters & $\begin{array}{l}\text { Core questionnaire } \\
\text { Process evaluation } \\
\text { parents/caregivers }\end{array}$ \\
\hline & \multirow[t]{7}{*}{ Knowledge } & K.1.a., K.1.b. & Active learning & $\mathrm{SCT}$ & Tip cards & Core questionnaire \\
\hline & & \multirow[t]{3}{*}{ K.1.a., K.1.b., K.2., K.3., } & \multirow{3}{*}{$\begin{array}{l}\text { Consciousness } \\
\text { raising (providing } \\
\text { information) }\end{array}$} & \multirow[t]{3}{*}{$\mathrm{HBM}$} & Tip cards & Core questionnaire \\
\hline & & & & & Newsletters & Core questionnaire \\
\hline & & & & & $\begin{array}{l}\text { Parent-child activities at } \\
\text { kindergarten }\end{array}$ & $\begin{array}{l}\text { Core questionnaire } \\
\text { Process evaluation } \\
\text { parents/caregivers }\end{array}$ \\
\hline & & K.2., K.4. & Discussion & $\mathrm{TIP}$ & $\begin{array}{l}\text { Parent-child activities at } \\
\text { kindergarten }\end{array}$ & Core questionnaire \\
\hline & & \multirow[t]{2}{*}{ K.3., K.4. } & \multirow[t]{2}{*}{ Guided practice } & \multirow[t]{2}{*}{$\mathrm{SCT}$} & Tip cards & Core questionnaire \\
\hline & & & & & Newsletters & Core questionnaire \\
\hline & \multirow[t]{4}{*}{ Attitude } & A.1., A.2., A.3., A.4. & Arguments & PCM & Newsletters & Core questionnaire \\
\hline & & A.1., A.2., A.4. & Self-reevaluation & $\mathrm{SCT}$ & Newsletters & Core questionnaire \\
\hline & & A.2., A.3., A.4. & Discussion & TIP & Newsletters & Core questionnaire \\
\hline & & & & & $\begin{array}{l}\text { Parent-child activities } \\
\text { at kindergarten }\end{array}$ & Core questionnaire \\
\hline & \multirow[t]{4}{*}{ Habit } & \multirow[t]{2}{*}{ H.1.a., H.3. } & \multirow[t]{2}{*}{ Guided practice } & \multirow[t]{2}{*}{$\mathrm{SCT}$} & Newsletters & Core questionnaire \\
\hline & & & & & Poster & Core questionnaire \\
\hline & & \multirow[t]{2}{*}{ H.1.a., H.1.b., H.3. } & \multirow[t]{2}{*}{ Modeling } & \multirow[t]{2}{*}{$\mathrm{SCT}$} & Newsletters & Core questionnaire \\
\hline & & & & & Tip cards & Core questionnaire \\
\hline & $\begin{array}{l}\text { Social } \\
\text { influence }\end{array}$ & SI.2. & $\begin{array}{l}\text { Resistance to social } \\
\text { pressure }\end{array}$ & TPB & Newsletters Tip cards & Core questionnaire \\
\hline \multirow[t]{2}{*}{ TEACHERS } & \multirow[t]{2}{*}{ Self-efficacy } & \multirow[t]{2}{*}{$\begin{array}{l}\text { SE.1.a., SE.1.b., SE.2., } \\
\text { SE.3., SE.4., SE.5. }\end{array}$} & \multirow[t]{2}{*}{ Guided practice } & \multirow[t]{2}{*}{$\mathrm{SCT}$} & Teachers' guide & $\begin{array}{l}\text { Teachers' questionnaire } \\
\text { Process evaluation } \\
\text { teachers }\end{array}$ \\
\hline & & & & & Teachers' training & $\begin{array}{l}\text { Process evaluation } \\
\text { teachers }\end{array}$ \\
\hline
\end{tabular}


Table 5 Theoretical methods and applications for achieving the change objectives at each level of the ToyBox-study intervention (Continued)

\begin{tabular}{|c|c|c|c|c|c|}
\hline & & & & $\begin{array}{l}\text { Classroom activities done } \\
\text { at kindergarten listed in } \\
\text { the handbook }\end{array}$ & $\begin{array}{l}\text { Teachers' questionnaire } \\
\text { Process evaluation } \\
\text { teachers }\end{array}$ \\
\hline & \multirow[t]{4}{*}{ SE.1.a., SE.1.b., SE.2. } & \multirow{4}{*}{$\begin{array}{l}\text { Consciousness } \\
\text { raising (providing } \\
\text { information) }\end{array}$} & \multirow[t]{4}{*}{$\mathrm{HBM}$} & Teachers' training & $\begin{array}{l}\text { Process evaluation } \\
\text { teachers }\end{array}$ \\
\hline & & & & Teachers' guide & $\begin{array}{l}\text { Process evaluation } \\
\text { teachers }\end{array}$ \\
\hline & & & & Stories of the kangaroo & $\begin{array}{l}\text { Teachers' questionnaire } \\
\text { Process evaluation } \\
\text { teachers }\end{array}$ \\
\hline & & & & $\begin{array}{l}\text { Classroom activities done at } \\
\text { kindergarten listed in the } \\
\text { handbook }\end{array}$ & $\begin{array}{l}\text { Teachers' questionnaire } \\
\text { Process evaluation } \\
\text { teachers }\end{array}$ \\
\hline & \multirow[t]{2}{*}{$\begin{array}{l}\text { SE.1.b., SE.2., SE.3., } \\
\text { SE.4., SE.5. }\end{array}$} & \multirow[t]{2}{*}{ Modeling } & \multirow[t]{2}{*}{$\mathrm{SCT}$} & Teachers' guide & $\begin{array}{l}\text { Teachers' questionnaire } \\
\text { Process evaluation } \\
\text { teachers }\end{array}$ \\
\hline & & & & Teachers' training & $\begin{array}{l}\text { Process evaluation } \\
\text { teachers }\end{array}$ \\
\hline & $\begin{array}{l}\text { SE.1.b., SE.2., } \\
\text { SE.4., SE.5. }\end{array}$ & Discussion & $\mathrm{TIP}$ & Teachers' training & $\begin{array}{l}\text { Process evaluation } \\
\text { teachers }\end{array}$ \\
\hline \multirow[t]{4}{*}{ Habit } & \multirow[t]{2}{*}{ H.2., H.3., H.4. } & \multirow[t]{2}{*}{ Modeling } & \multirow[t]{2}{*}{$\mathrm{SCT}$} & Teachers' training & $\begin{array}{l}\text { Process evaluation } \\
\text { teachers }\end{array}$ \\
\hline & & & & Teachers' guide & $\begin{array}{l}\text { Teachers' questionnaire } \\
\text { Process evaluation } \\
\text { teachers }\end{array}$ \\
\hline & \multirow[t]{2}{*}{ H.2., H.3., H.4. } & \multirow[t]{2}{*}{$\begin{array}{l}\text { Planning coping } \\
\text { responses }\end{array}$} & \multirow[t]{2}{*}{$\mathrm{TGDB}$} & Teachers' training & $\begin{array}{l}\text { Process evaluation } \\
\text { teachers }\end{array}$ \\
\hline & & & & Teachers' guide & $\begin{array}{l}\text { Teachers' questionnaire } \\
\text { Process evaluation } \\
\text { teachers }\end{array}$ \\
\hline \multirow[t]{4}{*}{ Knowledge } & \multirow[t]{3}{*}{$\begin{array}{l}\text { K.1.a., K.1.b., K.2., K.4., } \\
\text { K.5. }\end{array}$} & \multirow[t]{3}{*}{$\begin{array}{l}\text { Consciousness raising } \\
\text { (providing information) }\end{array}$} & \multirow[t]{3}{*}{$\mathrm{HBM}$} & Teachers' training & $\begin{array}{l}\text { Teachers' questionnaire } \\
\text { Process evaluation } \\
\text { teachers }\end{array}$ \\
\hline & & & & Teacher's guide & $\begin{array}{l}\text { Teachers' questionnaire } \\
\text { Process evaluation } \\
\text { teachers }\end{array}$ \\
\hline & & & & Stories of the kangaroo & Teachers' questionnaire \\
\hline & $\begin{array}{l}\text { K.1.a., K.1.b., K.2., K.4., } \\
\text { K.5. }\end{array}$ & Discussion & $\mathrm{TIP}$ & $\begin{array}{l}\text { Teachers' training } \\
\text { Parent-child activities } \\
\text { at kindergarten }\end{array}$ & $\begin{array}{l}\text { Teachers' questionnaire } \\
\text { Process evaluation } \\
\text { teachers }\end{array}$ \\
\hline \multirow[t]{3}{*}{ Attitude } & \multirow[t]{2}{*}{ A.3., A.4. } & \multirow[t]{2}{*}{$\begin{array}{l}\text { Consciousness raising } \\
\text { (providing information) }\end{array}$} & \multirow[t]{2}{*}{$\mathrm{HBM}$} & Teachers' training & $\begin{array}{l}\text { Teachers' questionnaire } \\
\text { Process evaluation } \\
\text { teachers }\end{array}$ \\
\hline & & & & Teachers' guide & $\begin{array}{l}\text { Teachers' questionnaire } \\
\text { Process evaluation } \\
\text { teachers }\end{array}$ \\
\hline & A.3., A.4. & Discussion & $\mathrm{TIP}$ & Teachers' training & $\begin{array}{l}\text { Teachers' questionnaire } \\
\text { Process evaluation } \\
\text { teachers }\end{array}$ \\
\hline \multirow[t]{2}{*}{$\begin{array}{l}\text { Social } \\
\text { influence }\end{array}$} & \multirow[t]{2}{*}{ SI.2., SI.3. } & \multirow[t]{2}{*}{$\begin{array}{l}\text { Resistance to social } \\
\text { pressure }\end{array}$} & \multirow[t]{2}{*}{ TPB } & Teachers' training & $\begin{array}{l}\text { Teachers' questionnaire } \\
\text { Process evaluation } \\
\text { teachers }\end{array}$ \\
\hline & & & & Teachers' guide & $\begin{array}{l}\text { Teachers' questionnaire } \\
\text { Process evaluation } \\
\text { teachers }\end{array}$ \\
\hline
\end{tabular}

*See Table 2, 3 and 4 for a full description of the change objectives.

† A description of the methods mentioned in Table 5 can be found Bartholomew et al. 2011, page 322, Table 6.4 until 6.16.

$¥$ SCT: Social Cognitive Theory; TIP: Theories of Information Processing; PCM: Persuasion-Communication Matrix; TL: Theories of Learning; TPB: Theory of Planned Behavior; GST: Goal-Setting Theory; TGDB: Theories of Goal Directed Behavior; HBM: Health Belief Model. 
Because parents are perceived as children's most important caregivers [37], the home environment at the interpersonal level was also included in the intervention. In order to involve the parents/caregivers in this kindergarten-based intervention, different educational materials were developed: a poster (to be colored by the preschoolers), two newsletters and two tip cards. Teachers were asked to hand out these materials to the parents/caregivers according to the provided time plan. In week 13 of the intervention, the poster and newsletter 1 were handed out. Following this, the first tip card on sedentary behavior was handed out in week 15. During the repetition period, the second newsletter and the second tip card were handed out in week 23 and week 24 respectively. The poster included key messages to decrease preschoolers' sedentary behavior at home (e.g., 'Don't sit down too long - stand up and be active'), newsletters included information about sedentary behavior and in the tip cards, different tips and strategies to decrease this behavior were mentioned. Furthermore, activities that parents/caregivers and children could perform together at home to decrease sedentary behavior were also suggested in the educational materials. Table 6 provides a detailed overview of what was included in the different intervention materials. After the end of the ToyBox-study (April 2014), all the different intervention materials will be available on the website (www.toyboxstudy.eu)

\section{Step 5: planning program adoption and implementation}

The strategic implementation of the intervention was planned during step five of the IMP. The ToyBox-study intervention was implemented in a cluster randomized controlled trial intervention with a pre-test posttest design including 300 kindergartens. Each kindergarten was assigned either to the intervention or control condition. In each participating kindergarten, at least one teacher and 20 preschoolers per class were included. In total, more than 7000 preschoolers and their parents/caregivers were targeted. Teachers in the intervention kindergartens focused on different behaviors for 24 weeks from October 2012 until the end of March 2013 (school year 2012-2013) and executed the sedentary behavior intervention from week 13 to week 17 and planned a repetition of this focus for two weeks in week 23 and 24 later that school year. During two different training sessions that were organized in the participating countries, teachers of the intervention schools were informed about their role as the implementers of the intervention and about the specific time plan of the intervention. Furthermore, the handbook and the different materials were presented, role play was done and teachers could discuss with each other how they would implement the intervention in their classroom.

\section{Step 6: evaluation planning}

In the final step of the IMP, a plan to evaluate the effectiveness of the evidence-based family-involved intervention targeting preschoolers was developed. After the 24 intervention weeks, the general effectiveness of the intervention was evaluated with regards to changes in anthropometric measures (BMI) and changes in behaviors related to the specific program objectives. For the sedentary behavior component of the ToyBox-study intervention, preschoolers' sedentary time was objectively measured with accelerometers in one country (Belgium) because these devices were available in this country. These measures were used to investigate whether preschoolers' sedentary time decreased by $10 \%$ at home and during the time spent at kindergarten during the day (program objective at the individual level). Furthermore, to investigate potential changes in screen viewing activities, parents/caregivers in all countries were asked to complete a questionnaire during baseline and posttest measurements about the amount of time their child spent watching TV, using the computer and performing quiet play. A new primary caregivers' questionnaire (i.e., core questionnaire) was developed for the ToyBox-study and reliability of this questionnaire was investigated. Results of this test-retest reliability showed that the core questionnaire is a reliable tool to assess behaviors of preschool children participating in a kindergarten intervention (González-Gil et al., unpublished data). This core questionnaire was used to investigate whether parents/ caregivers limited preschoolers' screen viewing activities at home to less than one hour (program objective at the interpersonal level). To investigate potential changes in preschool teachers' behavior at preschool, a teachers' questionnaire was developed that investigated whether kindergarten teachers limited preschoolers' screen viewing activities to less than one hour. This questionnaire was completed by teachers during baseline and posttest measurements and included specific questions about different strategies to interrupt prolonged periods of sitting, movement breaks, and possibilities to rearrange the classroom to decrease sedentary behavior, etc. before and after the intervention (program objective at the organizational level).

To evaluate the implementation of the intervention at home and in the kindergartens, process evaluation questionnaires were developed for the teachers and the parents/caregivers. This process evaluation identified the parental activities that parents/caregivers performed at home to decrease preschoolers' sedentary behavior and the activities teachers performed at preschool. After all questionnaires were developed and approved by all partners, they were translated from English into local languages. After the translation to the local language, these questionnaires were back translated to detect any 


\section{Table 6 Detailed description of the different applications used in the intervention}

1. Story 1: the kangaroo and his friends start an adventurous trip to the forest in search of a cave. The cat prefers to watch TV instead and the other animals wanting to change the cat's behavior, try to persuade her that a real adventure is much more fun compared to watching TV.

Handbook: Stories of the kangaroo and its friends (a cat, a $\quad$ 2. Story 2: the animals arrive at school only to discover that their teacher, Mrs. Owl, has mysteriously disappeared. They have to choose bear and a rabbit)

\section{Individual level and} 2. Story 2: the animals arrive at school only to discover that their teacher, Mrs. Owl, has myst
whether they will watch TV or start a new adventure and search for their favorite teacher.

organizatio

3. Story 3: the kangaroo received a new present; a pair of magic socks that stopped him from being sedentary. But in the end, the little kangaroo understands that it is not magic that makes him move; it is actually what his own body is asking for.

Short (1-5 minutes) movement breaks: e.g., 'Playing a statue': preschoolers have to walk through the classroom and when the teachers

Handbook: Classroom activities in the form of short and long movement breaks

short '(1-5 minutes) movement breaks: e.g., 'Playing a s
says 'STOP', they have to stay still for some seconds.

Long (15-20 minutes) movement breaks: e.g., preschoolers can walk through the classroom and when the teachers says 'SEARCH A FRIEND', each preschooler have to look for a friend to stand still for about 3 seconds.

Different activities were listed. For example:

Activities to be done while standing up (provided in the handbook and in the movement breaks)

- The teacher can remove the chairs and let the preschoolers paint or color on a raised desk

- Putting the sandbox on a raised desk for the preschoolers to play while standing up.

Repeated interruption moments at kindergarten

Kindergarten teachers could include repeated sitting interruption moments while preschoolers are at kindergarten. It is suggested in the handbook to interrupt prolonged periods of sitting down and set time rules to interrupt this behavior every 30 - 40 minutes.

Parents/caregivers are invited to participate in these parent-child activities and to come to the kindergarten where they can do nice activities together with their child (e.g. a role play).

The teachers' guide is developed for teachers and included the following topics:

- An explanation of why we need the ToyBox-study

Teachers' guide

- A description of all the different materials that are included in the ToyBox-study and how these materials should be used

- Some information on how they can be a team together with the parents/caregivers to change different preschoolers' behaviors.

All teachers from the intervention schools were invited to attend two different training sessions.

1. First training session (June 2012): a general introduction was given to the teachers, the teachers' guide was presented and the environmental changes teachers could perform in their classroom to change the different behaviors included in the ToyBox-study an

Teachers' training the different classroom activities were explained. At the end of the training, there was also some time for discussion.

2. Second training session (September - October 2012): teachers could first share experiences and a small repetition of the information provided in the first training was done. Afterwards, the teachers went through the classroom activities together with the researchers. provided in the first training was done. Afterwards
The second training was closed by a discussion.

Newsletters

A clear definition of sedentary behavior is included in the first newsletters and also the activities that cover this behavior are mentioned. Furthermore, also the recommendations for preschoolers' sedentary behavior and screen time are included in the newsletters.

Parents/caregivers are provided with different tips of how to decrease preschoolers' sedentary behavior (e.g., try to avoid that your child turns the TV on without your permission).

Tip cards

In these tip cards, parent-child activities that could be performed at home were suggested as well. For example, preschoolers and parents/caregivers could decrease their sedentary time by doing things in the household together instead of watching television together.

Interpersonal level

Four different key messages were mentioned

- 'Don't sit down for a long time, get up and be active'

'Include active movement breaks in the children's daily lives'

- 'Limit screen viewing activities - make your own experiences'

- 'Don't eat in front of screens'

On the posters, different pictures of the kangaroo were provided for the preschoolers to color. 
potential differences between the back translated and the original questionnaires. Finally, a health economic modeling model was used to analyze the cost effectiveness of the intervention. This model consisted of a decision analytic model to represent either the probability of improved healthy behavior or improved BMI category in preschoolers and of a Markov model simulating over a lifetime the occurrence of obesity-related complications with and without the early childhood intervention (Pil et al., unpublished data).

\section{Discussion}

The present paper described the evidence-based development of an intervention, focusing on sedentary behavior. This sedentary behavior intervention was the first intervention that targeted different forms of sedentary behavior. A description of the different steps towards the development of the intervention using the IMP is provided, including detailed information about the preparation of the matrices with change objectives, the selection of methods and applications and about the production of the intervention materials. The development of this intervention matched the systematic evidence-based approach of the IMP and was perceived as rather complex and time-consuming. The matrices and change objectives were developed by two countries and were afterwards discussed during the ToyBox-study meeting that took place in Ghent (Belgium) during the first week of March 2011. After all partners approved the matrices and change objectives, the matrices were finalized by the end of April 2011. The second step of the IMP took approximately four months and was considered as an iterative process, because drafts of matrices and change objectives were read, discussed and approved by the participating countries. Other studies that used the IMP for the development of an intervention also mentioned that this process was time-consuming [38,39]. Planners of future health interventions should take into consideration that planning an intervention using the IMP requires scientific staff and necessary funding. Even when researchers want to develop an intervention that is less complex, has less intervention levels (e.g., only the kindergarten level) or focuses on less behaviors, it is recommended to pay enough attention to the selection of these intervention developers and to ensure that at least of few of the intervention developers have experience with using the IMP and developing matrices. Furthermore, it is important to devote enough time on the execution of the different IMP steps to ensure that well-considered choices are made in the development and implementation of the intervention. Although this process was experienced taking much time and effort, it is an effective approach to making choices systematically for the development and implementation of an intervention. By making the process of the development of our intervention more transparent, we hope to convince intervention developers of the added value of using the IMP for the development of health promotion interventions. The detailed description of the IMP process will also be an aid for intervention developers in order to avoid repetitive work for the design of similar interventions.

Going through the different steps of the IMP, it became clear that two important agents for targeting preschoolers' sedentary behavior could be identified, namely the parents/caregivers and the teachers. The school setting provided an ideal opportunity to emphasize and to promote an active and healthy lifestyle in this age group [40] and to decrease preschoolers' sedentary behavior. In the European countries participating in the ToyBoxstudy intervention, enrolment rates of preschoolers in preschool classes or kindergartens are particularly high (between 95 - 99\%) [41]. Because of the high enrolment rate and because children are especially influenced by their family/parents and the kindergarten environment $[42,43]$, the inclusion of both these target groups was of high importance to decrease preschoolers' sedentary behavior. During the intervention, changing teachers' behavior and changes in the classroom environment that could easily be performed by the kindergarten teachers were targeted, while changes in kindergarten' policies were not included. Kindergarten' policies are often formulated and defined by higher executive boards, what makes these policies much more difficult to change during an intervention compared to a classroom environment. However, striving for a policy to limit screen time at kindergarten or to use it only for educational purposes might be an important strategy that could be included in further intervention studies.

Different reviews mentioned that indirect methods were mostly used to engage parents/caregivers [44-46]. Furthermore, parents of older children (10-12 year olds) emphasized that their child's behavior and not their own behavior should be targeted in interventions [47]. To ensure that parents/caregivers in our intervention did not feel like their own behavior was being targeted in particular, and that they were not overloaded with information, indirect methods were used to provide parents/ caregivers with information about appropriate sedentary behavior in preschoolers on a regular base. So far, only one study that aimed to decrease TV viewing time in Australian primary school children [48] has already used newsletters to provide parents/caregivers with tips on how sedentary behavior can be changed. However, the effectiveness of this indirect strategy in preschooler parents/caregivers is yet unknown. According to the IMP, a planning group that includes stakeholders should be established before the start of the development of the 
intervention. Because the ToyBox-study included six different European countries, establishing a planning group including community members, program implementers, etc. from all participating countries was not possible. To ensure that a meaningful participation of European stakeholders was obtained, focus groups were executed with parents/caregivers and teachers as the potential program participants. Each country was also advised to have close contact with stakeholders and implementers so that they could address important issues before, during and after the development of the intervention. In the literature, focus groups with parents/caregivers and preschool teachers have been executed to describe the influencing factors, barriers and facilitators of preschoolers' physical activity levels [49-52], but little information could be located about the most important predisposing, reinforcing and enabling factors of preschoolers' sedentary behavior. Therefore, parents/caregivers and teachers were invited to discuss their opinions on preschoolers' sedentary behavior. Although the execution of focus groups enabled us to collect primary data that could be used in the needs assessment to get a better insight into preschoolers' sedentary behavior at home and in the kindergarten environment, a well-functioning planning or working group might be even more able to interpret the needs and perspective of preschoolers and the target agents of the intervention.

Once results of the focus groups from all countries in the ToyBox-study were analyzed, general recommendations for the intervention were formulated and taken into account during the development of the intervention with the IMP. As suggested in another multi-center prevention program with activities for health promotion (namely, the IDEFICS study), specific focus group results and suggestions were used during the local and cultural adaptation of the intervention component [38]. Because results of the focus groups indicated some cultural differences between the participating countries, the formulation of general recommendations for the ToyBox-study was well thought-out. Planners of future interventions including different European countries are advised to ensure that local and cultural adaptations of the intervention, based on cultural differences between the countries, are possible. For the sedentary behavior module of the intervention, cultural adaptations were rather limited, because of sedentary behavior being a new behavior to parents/caregivers and preschool teachers. So, apart from the adaptations that had to be done for other behaviors (e.g., the availability of fruit in preschoolers differed largely across the European countries), the intervention module focusing on sedentary behavior was quite similar in all participating countries.

Because some adaptations to cultural differences between the countries were needed in the intervention materials for some behaviors, pre-testing the material in all intervention countries, as part of the fourth step in the IMP, was not possible. However, future planners of health promotion interventions are advised to devote enough time on pretesting the materials and on discussing intervention materials with the implementers. The implementers of interventions can potentially address important issues and possible traps about the materials that intervention developers can easily adapt. For example, Belgian preschool teachers' suggested that additional visual support (e.g., including illustrations in the kangaroo stories) in the stories would make it easier to read the stories to the preschoolers and would possibly transfer the information in a more successful way. By pre-testing the intervention materials, including successful theories of information processing [30] (p.443-448) and by adopting the materials in accordance with implementers' feedback, the quality of the intervention and the materials will increase even more and this will possibly have a positive effect on the effectiveness of the intervention. The feedback on the intervention materials provided by the teachers during and after the implementation will be taken into account when the intervention material is revised after the study has ended.

Results from the literature indicated that studies conducted on preschoolers' sedentary behavior mainly focused on decreasing preschoolers' screen viewing activities $[27,28]$ and changes in these behaviors were mainly measured. Results of the study by Dennison et al. [27] and Epstein et al. [28] indicated mainly changes in sedentary behavior measured by the amount of TV or video viewing, while in this intervention, changes in different forms of sedentary behaviors and changes in BMI were measured. To indicate possible effects of the intervention on time spent in screen viewing activities, subjective methods (i.e., a parental and a teachers' questionnaire) were used. In addition, objective measures of preschoolers' sedentary behavior were also assessed in one country (Belgium) to evaluate if the intervention was effective in decreasing preschoolers' total sedentary time. Future planners are suggested to make wellconsidered choices of how they will measure intervention effects. We believe that objective measures, in conjunction with subjective measures should be used to assess both total sedentary time and preschoolers' time spent in different sedentary activities.

\section{Conclusions}

A systematic approach using the IMP was used for the development of the intervention part of the ToyBoxstudy, which among others aimed to reduce different forms of sedentary behavior in preschoolers in six European countries. The second IMP step was proven to be the most iterative and time-consuming of all, as the 
development of matrices was a rather meticulous task. The final outcome of this IMP exercise was a standardized intervention that was implemented in the different participating European countries, with some minor adaptations to account for some cultural differences. Despite the fact that implementing IMP was a rather long and systematic process, the evidence-based development of this intervention could increase its effectiveness. Planners of future interventions are encouraged to carefully select the developers and ensure that enough time and money are available for the preparation of an intervention. Future intervention developers can use the matrices as an aid in order to avoid repetitive work for the development of their intervention.

\section{Abbreviations}

TV: Television; BMI: Body mass index; IMP: Intervention mapping protocol.

\section{Competing interests}

The authors declare that they have no competing interests.

\section{Authors' contributions}

All authors participated in the ToyBox-study and in the study design. All authors read, critically reviewed the manuscript and approved the final manuscript. EDD, MDC, IDB and GC were responsible for the development of the sedentary behavior intervention of the ToyBox-study. EDD wrote the manuscript.

\section{Acknowledgements}

The ToyBox-study is funded by the Seventh Framework Program (CORDIS FP7) of the European Commission under grant agreement $n^{\circ} 245200$. The content of this paper reflects only the authors' views and the European community is not liable for any use that may be made of the information contained therein. The data have been collected by the ToyBox investigators and have been made available for this publication by the ToyBox consortium. Views expressed in this paper are those of the authors and may not reflect those of ToyBox beneficiaries. The authors would like to thank Dr. Leigh Gibson for reviewing the manuscript and for making language corrections.

The ToyBox-study group consists of: Coordinator: Yannis Manios; Steering Committee: Yannis Manios, Berthold Koletzko, Ilse De Bourdeaudhuij, Mai Chin A Paw, Luis Moreno, Carolyn Summerbell, Tim Lobstein, Lieven Annemans, Goof Buijs; External Advisors: John Reilly, Boyd Swinburn, Dianne Ward; Harokopio University (Greece): Yannis Manios, George Boskou, Vassiliki Costarelli, Odysseas Androutsos, Eva Grammatikaki, Christina Katsarou, Eftychia Apostolidou, Anastasia Livaniou, Katerina Lymperopoulou; Ludwig Maximilians Universitaet Muenchen (Germany): Berthold Koletzko, Kristin Duvinage, Sabine Ibrügger, Angelika Strauß, Birgit Herbert, Julia Birnbaum, Annette Payr, Christine Geyer; Ghent University (Belgium): Department of Movement and Sports Sciences: Ilse De Bourdeaudhuij, Greet Cardon, Marieke De Craemer, Ellen De Decker and Department of Public Health: Lieven Annemans, Stefaan De Henauw, Lea Maes, Carine Vereecken, Jo Van Assche, Lore Pil; VU University Medical Center EMGO Institute for Health and Care Research (the Netherlands): EMGO Institute for Health and Care Research: Mai Chin A Paw, Saskia te Velde; University of Zaragoza (Spain): Luis Moreno, Theodora Mouratidou, Juan Fernandez, Maribel Mesana, Pilar De Miguel-Etayo, Esther González, Luis Gracia-Marco, Beatriz Oves; Oslo and Akershus University College of Applied Sciences (Norway): Agneta Yngve, Susanna Kugelberg, Christel Lynch, Annhild Mosdøl; University of Durham (UK): Carolyn Summerbell, Helen Moore, Wayne Douthwaite, Catherine Nixon; State Institute of Early Childhood Research (Germany): Susanne Kreichauf, Andreas Wildgruber; Children's Memorial Health Institute (Poland): Piotr Socha, Zbigniew Kulaga, Kamila Zych, Magdalena Góźdź, Beata Gurzkowska, Katarzyna Szot; Medical University of Varna (Bulgaria): Violeta lotova, Mina Lateva, Natalya Usheva, Sonya Galcheva, Vanya Marinova, Zhaneta Radkova, Nevyana Feschieva; International Association for the Study of Obesity (UK): Tim Lobstein, Andrea Aikenhead; National Institute for Health Promotion and Disease Prevention (the Netherlands): Goof Buijs, Annemiek Dorgelo, Aviva Nethe, Jan Jansen; AOK- Verlag (Germany): Otto Gmeiner, Jutta Retterath, Julia Wildeis, Axel Günthersberger; Roehampton University (UK): Leigh Gibson; University of Luxembourg (Luxembourg): Claus Voegele.

\section{Author details}

'Department of Movement and Sports Sciences, Ghent University, Watersportlaan 2, 9000 Ghent, Belgium. '2Division Metabolic and Nutritional Medicine, Dr. Von Hauner Children's Hospital, Ludwig-Maximilians-University of Munich, Lindwurmstr.4, D-80337 München, Germany. ${ }^{3}$ Clinic of Paeditric Endocrinology, UMHAT "St. Marina", Hr. Smirnenski Blvd, Varna, Bulgaria. ${ }^{4}$ Department of Nutrition and Dietetics, Harokopio University, 70 El. Venizelou ave, 17671 Kallithea, Greece. ${ }^{5}$ Staatsinstitut für Frühpädagogik (IFP), State Institute of Early Childhood Research, IFP, Winzererstr. 9, Eckgebäude Nord, 80797 München, Germany. 'University of Zaragoza, GENUD Group, Edificio Cervantes, C/ Corona de Aragón 42, 50009 Zaragoza, Spain.

Received: 7 August 2013 Accepted: 13 February 2014 Published: 19 February 2014

\section{References}

1. Tremblay MS, LeBlanc AG, Carson V, Choquette L, Gorber SC, Dillman C, Duggan M, Gordon MJ, Hicks A, Janssen I, Kho ME, Latimer-Cheung AE, LeBlanc C, Murumets K, Okely AD, Reilly JJ, Stearns JA, Timmons BW, Spence JC: Canadian sedentary behaviour guidelines for the early years (aged 0-4 years). Appl Physiol Nutr Metab 2012, 37(2):370-380.

2. Network SBR: Standardized use of the terms "sedentary" and "sedentary behaviours". Appl Physiol Nutr Metab 2012, 37:540-542.

3. Hancox RJ, Milne BJ, Poulton R: Association of television viewing during childhood with poor educational achievement. Arch Pediatr Adolesc Med 2005, 159:614-618

4. Mistry KB, Minkovitz CS, Strobino DM, Borzekowski DL: Children's television exposure and behavioral and social outcomes at 5.5 years: does timing of exposure matter? Pediatrics 2007, 120(4):762-769.

5. Janz KF, Burns TL, Torner JC, Levy SM, Paulos R, Willing MC, Warren J J: Physical activity and bone measures in young children: the lowa bone development study. Pediatrics 2001, 107(6):1387-1393.

6. Biddle SJH, Gorely T, Stensel DJ: Health-enhancing physical activity and sedentary behaviour in children and adolescents. J Sports Sci 2004, 22(8):679-701.

7. Hancox RJ, Poulton R: Watching television is associated with childhood obesity: but is it clinically important? Int J Obesity 2005, 30(1):171-175.

8. Marshall SJ, Biddle SJ, Gorely T, Cameron N, Murdey I: Relationships between media use, body fatness and physical activity in children and youth: a meta-analysis. Int J Obesity 2004, 28(10):1238-1246.

9. Department of Health and Ageing: Get Up \& Grow: Healthy Eating and Physical Activity for Early Childhood - Directors/Coordinators Book. ; 2009. http://www. health.gov.au/internet/main/publishing.nsf/Content/phd-gug-directorscoord.

10. Department of Health Physical Activity Health Improvement and Protection: Start Active, Stay Active A report on physical activity for health from the four home countries' Chief Medical Officers. 2011. https://www.gov.uk/ government/publications/start-active-stay-active-a-report-on-physicalactivity-from-the-four-home-countries-chief-medical-officers.

11. Clark J, Clements R, Guddemi M, Morgan D, Pica R, Pivarnik J, Rudisill M, Small E, Virgilio S: Active start: a statement of physical activity guidelines for children from birth to age 5. 2nd edition. Sewickley, PA: National Association for Sport and Physical Education; 2009.

12. Flemish Government Department Health and Family: Vlaamse consensustekst in verband met evenwichtige voeding en beweging, ten behoeve van zorgverstrekkers. 2012. https:/www.zorg-en-gezondheid.be/uploadedFiles/ NLsite_v2/Gezond_leven_en_milieu/Gezonde_voeding_en_beweging/ Eetexpert\%20project\%20consensustekst\%2025-07-2012.pdf.

13. American Academy of Pediatrics: Active healthy living: prevention of childhood obesity through increased physical activity. Pediatrics 2006, 117(5):1834-1842

14. Reilly JJ, Jackson DM, Montgomery C, Kelly LA, Slater C, Grant S, Paton JY: Total energy expenditure and physical activity in young Scottish children: mixed longitudinal study. Lancet 2004, 363(9404):211-212.

15. Cliff $D$, Janssen $X$ : Levels of habitual physical activity in early childhood. In Encyclopedia on Early Childhood Development. Edited by Tremblay R, Barr 
R, Peters R, Boivin M. Montreal, Quebec: Centre of Excellence for early childhood development; 2011:1-6.

16. Hinkley T, Salmon J, Okely AD, Crawford D, Hesketh K: Preschoolers' physical activity, screen time, and compliance with recommendations. Med Sci Sports Exerc 2012, 44(3):458-465

17. Marshall SJ, Gorely T, Biddle SJH: A descriptive epidemiology of screen-based media use in youth: a review and critique. $J$ Adolescence 2006, 29(3):333-349.

18. Cardon G, De Bourdeaudhuij I: Are preschool children active enough? Objectively measured physical activity levels. Res Q Exerc Sport 2008, 79(3):326-332

19. Dowda M, Brown WH, Mclver KL, Pfeiffer KA, O'Neill JR, Addy CL, Pate RR: Policies and characteristics of the preschool environment and physical activity of young children. Pediatrics 2009, 123(2):e261-e266.

20. Grontved A, Pedersen GS, Andersen LB, Kristensen PL, Moller NC, Froberg K: Personal characteristics and demographic factors associated with objectively measured physical activity in children attending preschool. Pediatr Exerc Sci 2009, 21(2):209-219.

21. Brown WH, Pfeiffer KA, Mclver KL, Dowda M, Addy CL, Pate RR: Social and environmental factors associated with preschoolers' nonsedentary physical activity. Child Dev 2009, 80(1):45-58.

22. Temple V, Naylor PJ, Rhodes RE, Higgins JW: Physical activity of children in family child care. Appl Physiol Nutr Metab 2009, 34(4):794-798.

23. Cardon G, Labarque V, Smits D, De Bourdeaudhuij I: Promoting physical activity at the pre-school playground: the effects of providing markings and play equipment. Prev Med 2009, 48(4):335-340.

24. Hannon JC, Brown BB: Increasing preschoolers' physical activity intensities: an activity-friendly preschool playground intervention. Prev Med 2008, 46(6):532-536.

25. Wahi G, Parkin PC, Beyene J, Uleryk EM, Birken CS: Effectiveness of interventions aimed at reducing screen time in children. A systematic review and meta-analysis of randomized controlled trials. Arch Pediatr Adolesc Med 2011, 165(11):979.

26. DeMattia $L$, Lemont $L$, Meurer $L$ : Do interventions to limit sedentary behaviours change behaviour and reduce childhood obesity? A critical review of the literature. Obes Rev 2007, 8(1):69-81.

27. Dennison BA, Russo TJ, Burdick PA, Jenkins PL: An intervention to reduce television viewing by preschool children. Arch Pediatr Adolesc Med 2004, 158:170-176.

28. Epstein $\mathrm{LH}$, Roemmich $\mathrm{JN}$, Robinson $\mathrm{J}$, Paluch RA, Winiewicz DD, Fuerch $\mathrm{JH}$, Robinson TN: A randomized trial of the effects of reducing television viewing and computer use on body mass index in young children. Arch Pediatr Adolesc Med 2008, 162(3):239-245.

29. Manios Y, Grammatikaki E, Androutsos O, Chinapaw MJ, Gibson EL, Buijs G, lotova V, Socha P, Annemans L, Wildgruber A, Mouratidou T, Yngve A, Duvinage $K$, de Bourdeaudhuij I, on behalf of the ToyBox-study group: A systematic approach for the development of a kindergarten-based intervention for the prevention of obesity in preschool age children: the ToyBox-study. Obes Rev 2012, 13(Suppl 1):3-12.

30. Bartholomew L, Parcel G, Kok G, Gottlieb N, Fernández M: Planning Health Promotion Programs: An Intervention Mapping Approach. 3rd edition. 2011.

31. Green L, Kreuter M: Health Program Planning: An Educational and Ecological Approach. 4th edition. New York: McGraw-Hill; 2005.

32. van Stralen M, te Velde SJ, van Nassau F, Brug J, Grammatikaki E, Maes L, De Bourdeaudhuij I, Verbestel V, Galcheva S, lotova V, Koletzko BV, von Kries R, Bayer O, Kulaga Z, Serra-Majem L, Sánchez-Villegas A, Ribas-Barba L, Manios Y, Chinapaw MJ, on behalf of the ToyBox-study group: Weight status of European preschool children and associations with family demographics and energy balance-related behaviours: a pooled analysis of six European studies. Obes Rev 2012, 13(Suppl1):29-41.

33. te Velde S, van Nassau F, Uijtdewilligen L, van Stralen MM, Cardon G, De Craemer M, Manios Y, Brug J, Chinapaw MJ, on behalf of the ToyBox-study group: Energy balance-related behaviours associated with overweight and obesity in preschool children: a systematic review of prospective studies. Obes Rev 2012, 13(Suppl 1):56-74.

34. De Decker E, De Craemer M, De Bourdeaudhuij I, Wijndaele K, Duvinage K, Koletzko B, Grammatikaki E, lotova V, Usheva N, Fernández-Alvira JM, Zych K, Manios Y, Cardon G, on behalf of the ToyBox-study group: Influencing factors of screen time in preschool children: an exploration of parents' perceptions through focus groups in six European countries. Obes Rev 2012, 13(Suppl 1):75-84.
35. De Decker E, De Craemer M, De Bourdeaudhuij I, Wijndaele K, Duvinage K, Androutsos O, lotova V, Lateva M, Alvira JM, Zych K, Manios Y, Cardon G: Influencing factors of sedentary behavior in European preschool settings: an exploration through focus groups with teachers. J Sch Health 2013, 83:654-661.

36. Nixon C, Moore HJ, Douthwaite W, Gibson EL, Vogele C, Kreichauf S, Wildgruber A, Manios Y, Summerbell CD, on behalf of the ToyBox-study group: Identifying effective behavioural models and behaviour change strategies underpinning preschooland school-based obesity prevention interventions aimed at 4-6-year-olds: a systematic review. Obes Rev 2012, 13(Suppl. 1):106-117.

37. Golan M, Crow S: Parents are key players in the prevention and treatment of weight-related problems. Nutr Rev 2004, 62(1):39-50.

38. Verbestel V, De Henauw S, Maes L, Haerens L, Mårild S, Eiben G, Lissner L, Moreno LA, Frauca NL, Barba G, Kovács E, Konstabel K, Tornaritis M, Gallois K, Hassel H, De Bourdeaudhuij I: Using the intervention mapping protocol to develop a community-based intervention for the prevention of childhood obesity in a multi-centre European project: the IDEFICS intervention. Int J Behav Nutr Phys Act 2011, 8(1):82.

39. Reinaerts E, Nooijer JD, Vries D: Using intervention mapping for systematic development of two school-based interventions aimed at increasing children's fruit and vegetable intake. Health Educ 2008, 108(4):301-320.

40. Story M, Kaphingst KM, French S: The role of schools in obesity prevention. Future Child 2006, 16(1):109-142

41. Organisation for Economic Co-operation and Development (OECD): Enrolment in preschool and child care. 2011. http://www.oecd.org/els/soc/ PF3.2\%20Enrolment\%20in\%20childcare\%20and\%20preschools\%20-\% 20290713.pdf

42. Dowda M, Pfeiffer KA, Brown WH, Mitchell JA, Byun W, Pate RR: Parental and environmental correlates of physical activity of children attending preschool. Arch Pediatr Adolesc Med 2011, 165(10):939-944.

43. Ward DS: Physical activity in young children: the role of childcare. Med Sci Sports Exerc 2010, 42(3):499-501.

44. Roseman M, Riddell M, Haynes J: A content analysis of kindergarten-12th grade school-based nutrition interventions: taking advantage of past learning. J Nutr Educ Behav 2011, 43(1):2-18.

45. O'Connor T, Jago R, Baranowski T: Engaging parents to increase youth physical activity a systematic review. Am J Prev Med 2009, 37(2):141-149.

46. Hingle M, O'Connor TM, Dave JM, Baranowski T: Parental involvement in interventions to improve child dietary intake: a systematic review. Prev Med 2010, 51(2):103-111.

47. Van Lippevelde W, Verloigne M, De Bourdeaudhuij I, Bjelland M, Lien N, Fernández-Alvira JM, Moreno LA, Kovacs E, Brug J, Maes L: What do parents think about parental participation in school-based interventions on energy balance-related behaviours? A qualitative study in 4 countries. BMC Public Health 2011, 11(1):881.

48. Salmon J, Ball K, Hume C, Booth M, Crawford D: Outcomes of a group-randomized trial to prevent excess weight gain, reduce screen behaviours and promote physical activity in 10-year-old children: Switch-Play. Int J Obes 2008, 32(4):601-612.

49. Haerens L, De Bourdeaudhuij I, Eiben G, Lauria F, Bel S, Keimer K, Kovács E, Lasn H, Regber S, Shiakou M, Maes L: Formative research to develop the IDEFICS physical activity intervention component: findings from focus groups with children and parents. J Phys Act Health 2010, 7:246-256.

50. Dwyer GM, Higgs J, Hardy LL, Baur LA: What do parents and preschool staff tell us about young children's physical activity: a qualitative study. Int J Behav Nutr Phys Act 2008, 5(1):66.

51. O'Connor JP, Temple VA: Constraints and facilitators for physical activity in family day care. AJEC 2005, 30(4):1-9.

52. Pocock M, Trivedi D, Wills W, Bunn F, Magnusson J: Parental perceptions regarding healthy behaviours for preventing overweight and obesity in young children: a systematic review of qualitative studies. Obes Rev 2010, 11(5):338-353.

doi:10.1186/1479-5868-11-19

Cite this article as: De Decker et al:: Using the intervention mapping protocol to reduce European preschoolers' sedentary behavior, an application to the ToyBox-Study. International Journal of Behavioral Nutrition and Physical Activity 2014 11:19. 